\title{
INFLUÊNCIA DA ÉPOCA DE ESTOCAGEM NA QUALIDADE DA BIOMASSA FLORESTAL PARA A GERAÇÃO DE ENERGIA
}

\author{
Martha Andreia Brand ${ }^{1}$, José Otávio Brito ${ }^{2}$, Waldir Ferreira Quirino ${ }^{3}$, Graciela Inês Bolzon de Muñiz ${ }^{4}$ \\ ${ }^{1}$ Eng $^{\mathrm{a}}$ Florestal, Dr ${ }^{\mathrm{a}}$., Depto. de Engenharia Florestal, UDESC, Lages, SC, Brasil - a2mab@ cav.udesc.br \\ ${ }^{2}$ Eng. Florestal. Dr., Depto. de Ciências Florestais, ESALQ/USP, Piracicaba, SP, Brasil - jobrito@usp.br \\ ${ }^{3}$ Eng. Florestal. Dr., Serviço Florestal Brasileiro, MMA, Brasília, DF, Brasil - waldir.quirino@ florestal.gov.br \\ ${ }^{4}$ Eng $^{\mathrm{a}}$ Florestal, Dr ${ }^{\mathrm{a}}$., Depto. de Engenharia e Tecnologia Florestal, UFPR, Curitiba, PR, Brasil - gbmunize@ ufpr.br
}

Recebido para publicação: 28/05/2010 - Aceito para publicação: 17/02/2012

\begin{abstract}
Resumo
Este trabalho objetivou determinar a época de estocagem ideal para a melhoria da qualidade da biomassa florestal para geração de energia. O experimento foi realizado em Lages, SC, entre outubro de 2003 e fevereiro de 2005. Foram avaliados 4 lotes de toras com casca de Pinus taeda e Eucalyptus dunnii, em pilhas, com amostragem nas seguintes condições: material recém-colhido, com dois, quatro e seis meses de estocagem. O lote 1 foi armazenado entre outubro (2003) e maio (2004), o lote 2 , de janeiro a agosto de 2004, o lote 3, de maio a novembro de 2004 e o lote 4 , de agosto de 2004 a fevereiro de 2005. As propriedades avaliadas foram: teor de umidade na base úmida, poder calorífico superior e líquido. A época de estocagem teve influência sobre a qualidade energética da biomassa durante a estocagem, com alterações na umidade e poder calorífico líquido. Para ambas as espécies, as melhores épocas de estocagem foram entre agosto e fevereiro (lote 4) e outubro e maio (lote 1), com as maiores perdas de umidade e maiores ganhos energéticos. Portanto, a biomassa florestal colhida na saída do inverno ou início da primavera, que permaneceu sob estocagem durante o verão até o início do inverno, apresentou melhor qualidade energética.

Palavras-chave: Energia; Pinus taeda; Eucalyptus dunnii.
\end{abstract}

\begin{abstract}
Influence of the storage season over the quality of wood fuel. This study aimed to determine the optimal storage season for improving the quality of forest biomass for energy generation. The experiment was carried out in Lages, Brazil, between October 2003 and February 2005. 4 lots of Pinus taeda and Eucalyptus dunnii logs were stocked, in piles, with samples collected from the freshly harvested material, with two, four and six months of storage. The lot 1 was stored between October (2003) and May (2004), lot 2 (January-August (2004)), lot 3 (May-November (2204)) and 4 (August (2004)-February (2005)). The evaluated properties were as follows: moisture content on wet basis, gross and net calorific value. The storage season had influence on the biomass quality, with changes in moisture content and net calorific value. For both species, the best storage season was between August and February (lot 4) and from October to May (lot 1), with the greatest loss of moisture and higher energy savings. Therefore, forest biomass harvested in late winter or early spring, which remained in storage during the summer up to early winter had a better energy quality.

Keywords: Energy; Pinus taeda; Eucalyptus dunnii
\end{abstract}

\section{INTRODUÇÃO}

A época do ano tem influência sobre o comportamento da biomassa florestal durante a estocagem (HEDING, 1984; THÖRNQVIST, 1984b, 1985; NURMI, 1995; GARSTANG et al., 2002; PETTERSSON; NORDFJELL, 2007; NURMI; HILLEBRAND, 2007; NORD-LARSEN et al., 2011).

Segundo Nurmi e Hillebrand (2007), a qualidade energética da biomassa durante a estocagem pode ser avaliada principalmente pela variação no teor de umidade, que é o fator determinante. Outras análises incluem a densidade a granel, teor de cinzas, a presença de micro-organismos xilófagos e o poder calorífico.

Segundo Heding (1984), Nurmi (1995), Jirjis (1995) e Pettersson e Nordfjell (2007), na Dinamarca, Finlândia, Suécia e norte da Escandinávia, respectivamente, a secagem da biomassa florestal, 
tanto de árvores isoladas quanto de toras, resíduos florestais em pilhas, árvores jovens compactadas e resíduo florestal compactado e não compactado (estocado em leiras) é mais rápida nos meses de verão, ocorrendo reumidecimento do material durante o outono e o inverno se a estocagem ultrapassar os meses mais favoráveis à secagem, ou em épocas de maior umidade. Pettersson e Nordfjell (2007) destacam ainda que a estocagem de resíduos de colheita na forma compactada (fardos cilíndricos de $0,7 \mathrm{~m}$ de diâmetro e 3,4 m de comprimento) tem menor reumidecimento durante o inverno que o material não compactado, que é estocado em leiras. A realização de cobertura nas pilhas também tem um efeito positivo na perda eficiente de umidade durante a estocagem (PETTERSSON; NORDFJELL, 2007; NURMI; HILLEBRAND, 2007). Além disso, essa prática também contribui para o menor efeito do clima e das estações do ano sobre as variações observadas no teor de umidade entre inverno e verão (PETTERSSON; NORDFJELL, 2007).

Thörnqvist (1984b) observou o fenômeno das variações climáticas na perda de umidade da biomassa, na Suécia, quando resíduos de colheita florestal de Picea e Pinus foram processados durante o inverno e deixados na área de colheita. Nessa condição, o conteúdo de umidade diminuiu durante o verão (26 a $29 \%$ ) e aumentou novamente no outono ( 40 a $46 \%$ na base úmida). Porém, quando esses resíduos foram processados, coletados e empilhados no local de uso final, o conteúdo de umidade decresceu para teores entre 40 e $45 \%$ na base úmida, durante o verão e o outono.

Quando a biomassa é estocada em local bem ventilado, o teor de umidade diminui para valores inferiores a $40 \%$ após o período de um verão. As pilhas cobertas tiveram ainda uma redução de $6 \%$ na umidade em comparação com as pilhas não cobertas, sendo que o efeito da cobertura é mais importante na primavera, quando ocorre o derretimento da neve, enquanto que no inverno é menos sentida, pois a neve permanece no estado sólido, tendo menos influência na variação da umidade (NURMI; HILLEBRAND, 2007).

Portanto, de forma geral, na estocagem de lenha na forma de pilha, após a colheita, o teor de umidade diminuiu muito rapidamente para um nível relativamente estável. Depois de atingir a estabilidade, ocorrem variações sazonais, com teor de umidade relativamente alto durante o inverno e baixo durante o verão, sendo que a variação sazonal é menos pronunciada em pilhas cobertas (NORD-LARSEN et al., 2011).

Além disso, o tamanho da pilha também contribui para a velocidade de secagem do material estocado. Em pilhas pequenas, em torno de $120 \mathrm{~m}^{3}$, ocorre maior variação do teor de umidade em função da época de estocagem (THÖRNQVIST, 1985), sendo que o conteúdo de umidade decresceu de aproximadamente 50 para $40 \%$ depois de um inverno e verão estocados, na Suécia. Jirjis (1995) complementa que o conteúdo de umidade da biomassa na forma de toras decresce rapidamente se o material é estocado em pequenas pilhas durante o verão, com maior risco de reumidecimento no caso de épocas de alta umidade. Já nas grandes pilhas, em torno de $600 \mathrm{~m}^{3}$, a variação do teor de umidade em função da época é menor, havendo maior homogeneidade nesse teor.

Segundo Röser et al. (2011), a umidade também varia significativamente nas diferentes partes das pilhas, especialmente quando as pilhas não são cobertas, estabelecendo-se um gradiente decrescente a partir do topo para a base.

Portanto, o teor de umidade na base úmida da biomassa florestal varia sazonalmente, dependendo das condições meteorológicas e taxa de transpiração da espécie estocada (PETTERSSON; NORDFJELL, 2007). Andersson et al. (2002) destacam que a taxa de secagem depende de muitos fatores, incluindo temperatura ambiente, umidade relativa, velocidade do vento, estação do ano, precipitação, espécies de árvores e tamanho da árvore ou da biomassa estocada. Com relação às diferentes espécies estocadas, Nord-Larsen et al. (2011), avaliando a estocagem de lenha de Picea abies (L.) H. Karst., Fagus sylvatica L., Quercus robur L. e Acer pseudoplatanus L., verificou grandes diferenças na taxa de secagem entre as espécies. A taxa de secagem foi significativamente maior para Picea (conífera) em relação às espécies de folhosas. Isso foi devido provavelmente à difusão mais rápida da água em função da maior permeabilidade da madeira da conífera, apesar de o teor de umidade ser maior no momento da colheita. Essa espécie, se cortada no verão, estará com teor de umidade aceitável para geração de energia no iníco do inverno. No entanto, essa vantagem somente se mantém se as pilhas forem cobertas nos períodos de reumidecimento (outono e inverno). Em contrapartida, se a lenha é cortada no final do verão ou outono, o teor de umidade não atinge os valores desejados até o inverno. Já as folhosas tiveram menor teor de umidade inicial, mas também uma menor taxa de secagem. A madeira colhida durante o inverno ou início da primavera e estocada sob cobertura chegou ao teor de umidade desejado 
antes do próximo inverno. Quando a madeira foi cortada durante o verão ou outono, ou quando as pilhas não foram cobertas, o teor de umidade não foi atingido antes do início do inverno do ano seguinte.

Com relação ao poder calorífico, a biomassa oriunda da colheita florestal na Escandinávia, que foi produzida e coletada durante o inverno, teve aumento do seu conteúdo energético quando estocada em grandes pilhas, na forma de toras, nos estaleiros das áreas de colheita, por períodos de tempo entre três a nove meses. Até certo ponto, esse aumento foi devido à secagem do material, ao mesmo tempo em que a perda de massa foi pequena (THÖRNQVIST, 1984a).

Se a biomassa é produzida no inverno e permanece na área de colheita, espalhada pelo campo até o verão, antes da coleta e transformação em partículas, então o conteúdo de energia não é alterado. No entanto, se a coleta e o cavaqueamento da biomassa florestal forem realizados antes do inverno, o conteúdo de energia diminui. Em suma, do trabalho desenvolvido por Thörnqvist (1984a) pode-se concluir que, se a biomassa for produzida no inverno e estocada, na forma de toras, em pilhas, até o verão, existe ganho no poder calorífico, enquanto que, se o material for reduzido em partículas antes do inverno, existem perdas energéticas. Thörnqvist (1986) complementa que as variações energéticas dependem ainda das diferentes espécies de árvores e conteúdos de umidade no momento da confecção das pilhas e também dos diferentes métodos de preparação das pilhas.

A época do ano em que a estocagem é feita determina, em maior ou menor grau, o tempo necessário para que a biomassa florestal alcance as condições ótimas para a geração de energia. Além disso, o clima pode determinar a obrigatoriedade de realização da estocagem, principalmente em regiões onde as condições climáticas de determinada época do ano sejam tão adversas que impeçam a colheita ou acesso à biomassa (como, por exemplo, em regiões com inverno muito rigoroso ou estação de chuva bem definida e intensa) (HEDING, 1984; THÖRNQVIST, 1984b; NURMI, 1992 e 1995; GARSTANG et al., 2002; ANDERSSON et al., 2002; PETTERSSON; NORDFJELL, 2007; NURMI; HILLEBRAND, 2007; NORD-LARSEN et al., 2011).

No entanto, não é somente o clima que determina se a estocagem será ou não realizada. Outros fatores, como sazonalidade na demanda e oferta de energia, contribuem para a realização da estocagem da biomassa. Com relação à sazonalidade, alguns países têm maior demanda nos meses de inverno, principalmente se for necessário o uso de sistemas de aquecimento, enquanto que em outros a demanda pode ser maior no verão. Esse último exemplo se aplica ao Brasil, pois, devido à maior parte da energia ser de origem hidrelétrica, em algumas regiões, em função da estiagem, o potencial de produção é diminuído, enquanto a demanda energética aumenta, até pela necessidade de refrigeração dos ambientes pela característica tropical do país.

No caso específico da biomassa florestal, a oferta de determinado tipo de matéria-prima e seu preço podem determinar a realização da estocagem, independentemente da época do ano. Um exemplo usual disso é a estocagem da madeira na forma de toras, oriundas de desbastes. Em épocas onde estão sendo realizados desbastes de forma intensiva, pode haver no mercado grande disponibilização de toras com pequenos diâmetros. Estas, por sua vez, não serão completamente absorvidas pelas indústrias de celulose e papel ou de painéis, fazendo seu valor de mercado diminuir. Assim, esse material passa a ser utilizado no mercado de energia, propiciando a necessidade de estocagem, para regular o consumo pela planta geradora de energia.

Em última análise, a estocagem pode ser realizada independentemente dos fatores anteriormente mencionados. Nesse caso, essa operação é realizada com o objetivo de controlar as propriedades físicas e químicas da biomassa, para melhorar seu desempenho nos processos de geração de energia.

Portanto, em todos os casos anteriormente mencionados, foi importante determinar quais eram as melhores épocas de colheita da biomassa e em que época a estocagem contribuiu de forma mais significativa para a melhoria das propriedades da matéria-prima destinada à geração de energia. $\mathrm{O}$ conhecimento desses aspectos também determina o tempo ideal de estocagem.

Assim, para o desenvolvimento deste trabalho, partiu-se da hipótese de que a época do ano em que a estocagem é feita influencia na variação e qualidade das propriedades energéticas da madeira, e também, em maior ou menor grau, no tempo necessário para que a biomassa florestal alcance as condições ótimas para a geração de energia. Dessa forma, levando-se em consideração as questões levantadas anteriormente, este trabalho teve o objetivo de determinar a época de estocagem ideal para a utilização da biomassa florestal na geração de energia, através da análise da influência dessa variável sobre as propriedades físicas e químicas da biomassa importantes para o uso na geração de energia. 


\section{MATERIAL E MÉTO DOS}

O estudo foi realizado em Lages, Santa Catarina, entre outubro de 2003 e fevereiro de 2005. A cidade fica situada a $27^{\circ} 30^{\prime}$ de latitude Sul e a $50^{\circ}$ de longitude Oeste, com altitude entre 800 e $900 \mathrm{~m}$. Conforme a classificação climática de Köppen, essa região pertence ao tipo $\mathrm{Cfb}$, caracterizado por verão fresco e sem apresentar déficit hídrico (LEITE et al., 1973). Os dados meteorológicos do período de estudo estão apresentados na tabela 1.

Tabela 1. Condições climáticas de Lages, SC (outubro de 2003 a fevereiro de 2005) ${ }^{1}$.

Table 1. Climatic conditions in Lages, SC (October 2003 to February 2005).

\begin{tabular}{lcccccccccccccccccc}
\hline Dados & \multicolumn{1}{c}{$\mathbf{2 0 0 3}$} & Out & Nov & Dez & Jan & Fev & Mar & Abr & Mai & Jun & Jul & Ago & Set & Out & Nov & Dez & Jan & Fev \\
\hline $\begin{array}{l}\text { Precipitação } \\
\text { (mm) }\end{array}$ & 119 & 94 & 225 & 81 & 114 & 144 & 82 & 103 & 28 & 233 & 52 & 278 & 162 & 104 & 136 & 147 & 47 \\
$\begin{array}{l}\text { Temperatura } \\
\left({ }^{\circ} \mathrm{C}\right)\end{array}$ & 18 & 19 & 20 & 21 & 21 & 20 & 19 & 13 & 13 & 12 & 14 & 17 & 17 & 19 & 20 & 22 & 22 \\
$\begin{array}{l}\text { Umidade } \\
\text { relativa (\%) }\end{array}$ & 76 & 72 & 79 & 78 & 76 & 77 & 83 & 85 & 82 & 84 & 77 & 82 & 75 & 76 & 76 & 76 & 75 \\
\hline
\end{tabular}

Fonte: Empresa de Pesquisa Agropecuária e Extensão Rural de Santa Catarina (EPAGRI, 2006)

Foram utilizadas toras com casca de Pinus taeda L. e Eucalyptus dunnii Maiden, com diâmetros variados e comprimento médio de $2,4 \mathrm{~m}$. Cada espécie foi estocada, separadamente, em pilhas $(6 \mathrm{~m} \mathrm{de}$ comprimento x 2,5 m de largura x 2,5 m de altura).

O delineamento experimental utilizado foi do tipo fatorial, tendo como objetivo principal a avaliação da influência da época de estocagem sobre a qualidade da biomassa florestal. Para tanto, foram avaliadas as variáveis tempo de estocagem e espécies de madeira, em diferentes épocas do ano, através da medição das propriedades da biomassa importantes para a geração de energia.

Assim, o trabalho consistiu em quatro tratamentos (épocas do ano). As épocas de estocagem foram outubro a maio (Lote 1), janeiro a agosto (Lote 2), maio a novembro (Lote 3) e agosto a fevereiro (Lote 4) (Tabela 2). Em cada tratamento foram feitas quatro coletas (tempo de estocagem - biomassa recém-colhida, dois, quatro e seis meses de armazenamento). Em cada coleta, as amostras de cada espécie (Pinus taeda e Eucalyptus dunnii) foram compostas por dez toras retiradas de cada pilha e convertidas em uma amostra de laboratório para cada espécie.

$\mathrm{Na}$ tabela 2, as zonas escuras indicam o período de avaliação dos lotes, e os X marcados indicam os momentos de coleta no experimento.

Tabela 2. Delineamento experimental utilizado no estudo de estocagem de biomassa.

Table 2. Experimental design used in the study.

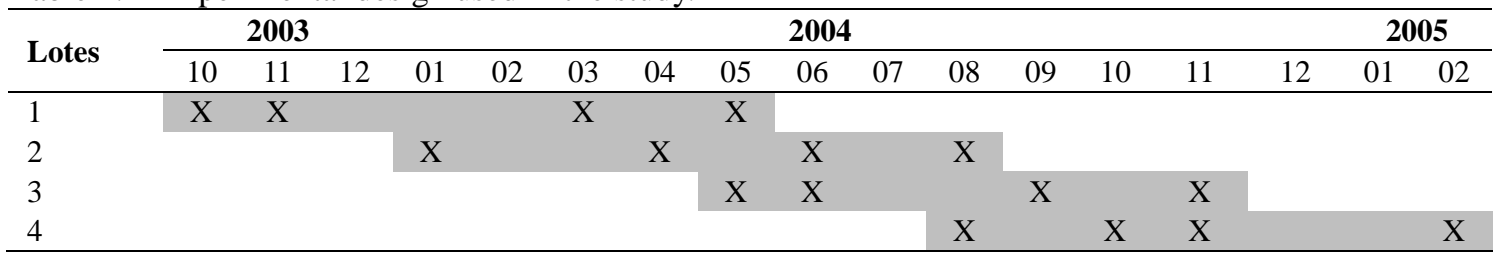

A influência do diâmetro das toras não foi avaliada no experimento ${ }^{2}$. No entanto, para minimizar o efeito dessa variável, em cada coleta foram retiradas dez toras de cada pilha, com diâmetros variados, de forma a representar a amplitude diamétrica existente na biomassa.

As amostras foram coletadas na base, meio e topo das pilhas. Sem haver remoção da casca, as toras foram transformadas em cavacos, utilizados na determinação das propriedades físicas e químicas. $\mathrm{O}$

1 A precipitação total do ano de 2004 foi de $1517 \mathrm{~mm}$, e os valores médios de temperatura e umidade relativa foram $17{ }^{\circ} \mathrm{C}$ e $79 \%$, respectivamente. Os dados apresentados refletem as condições climáticas de anos típicos na região.

2 Os diâmetros das toras variaram de 8 a mais de $30 \mathrm{~cm}$, pois o material de estudo foi constituído de madeira destinada à geração de energia (toras finas) e toras descartadas em processos industriais (toras grossas). 
teor de umidade na base úmida, poder calorífico superior e líquido foram analisados segundo as normas NBR 14929 e DIN 51900, respectivamente.

O poder calorífico superior foi determinado em calorímetro, em que a amostra é testada em câmara hermeticamente fechada, estando a $0 \%$ de umidade e com uso do comburente oxigênio a $99 \%$ de pureza. Portanto, esse valor é teórico, pois considera o potencial energético total do combustível, sem descontar a energia perdida na reação da evaporação da água formada a partir do hidrogênio de constituição. Dessa forma, o poder calorífico inferior, calculado a partir do poder calorífico superior e da porcentagem de hidrogênio do combustível, é a energia útil, pois desconta a energia necessária para a eliminação do hidrogênio de constituição. No entanto, esse valor não se aplica a combustíveis que têm água livre em sua estrutura, como o caso da biomassa. Nesse caso, é necessária a determinação do poder calorífico líquido, calculado a partir do poder calorífico inferior, da porcentagem de cinzas e do teor de umidade na base úmida do combustível. Neste último, além da energia para eliminação do hidrogênio de constituição, é descontada a energia necessária para a evaporação da água livre na madeira (PETTERSSON; NORDFJELL, 2007; BRAND, 2010). As três categorias de poder calorífico foram determinadas diretamente no calorímetro, que tem em seu software embutida a norma DIN 51900, baseada nos conceitos acima mencionados.

$\mathrm{O}$ tratamento estatístico foi feito através do teste $\mathrm{F}$, para verificação de variação significativa, e confirmação da variação através do teste de média de Tukey $(\mathrm{P}>0,05)$, considerando na análise a interação entre os fatores época de estocagem, tempo de estocagem e espécie estocada.

\section{RESULTADOS E DISCUSSÕES}

\section{Teor de umidade}

A época de estocagem teve influência sobre o comportamento da biomassa em relação à perda de umidade ao longo do tempo de estocagem, e de forma diferenciada para as toras de Eucalyptus dunnii e Pinus taeda (Tabela 3 e Figura 1).

Tabela 3. Teor de umidade na base úmida da biomassa florestal em função da época de estocagem. Table 3. Moisture content of forest biomass as a function of storage season.

\begin{tabular}{|c|c|c|c|c|}
\hline \multirow[b]{2}{*}{ Época de estocagem } & \multicolumn{4}{|c|}{ Teor de umidade na base úmida (\%) } \\
\hline & $\begin{array}{c}\text { Lote } 1 \\
\text { (outubro a maio) } \\
\end{array}$ & $\begin{array}{c}\text { Lote } 2 \\
\text { (janeiro a agosto) } \\
\end{array}$ & $\begin{array}{c}\text { Lote } 3 \\
\text { (maio a novembro) } \\
\end{array}$ & $\begin{array}{c}\text { Lote } 4 \\
\text { (agosto a fevereiro) }\end{array}$ \\
\hline \multicolumn{5}{|c|}{ Pinus taeda com casca } \\
\hline Recém-colhido & $56 \mathrm{c}$ & $55 \mathrm{c}$ & $65 \mathrm{a}$ & $61 \mathrm{~b}$ \\
\hline 2 meses & $62 \mathrm{a}$ & $52 \mathrm{c}$ & $63 \mathrm{a}$ & $55 \mathrm{~b}$ \\
\hline 4 meses & $25 \mathrm{c}$ & $56 \mathrm{a}$ & $57 \mathrm{a}$ & $44 \mathrm{~b}$ \\
\hline 6 meses & $50 \mathrm{~b}$ & $54 \mathrm{a}$ & $56 \mathrm{a}$ & $45 \mathrm{c}$ \\
\hline \multicolumn{5}{|c|}{ Eucalyptus dunnii com casca } \\
\hline Recém-colhido & $53 \mathrm{~b}$ & $50 \mathrm{c}$ & $58 \mathrm{a}$ & $53 \mathrm{~b}$ \\
\hline 2 meses & $44 \mathrm{~b}$ & $39 \mathrm{c}$ & $52 \mathrm{a}$ & $36 \mathrm{~d}$ \\
\hline 4 meses & $33 \mathrm{c}$ & $41 \mathrm{a}$ & $35 \mathrm{~b}$ & $28 \mathrm{~d}$ \\
\hline 6 meses & $28 \mathrm{c}$ & $37 \mathrm{a}$ & $33 \mathrm{~b}$ & $28 \mathrm{c}$ \\
\hline
\end{tabular}

Com relação ao teor de umidade da biomassa colhida nas diferentes épocas do ano (toras recémcolhidas), os maiores teores de umidade observados foram nos lotes 3 (maio) e 4 (agosto), tanto para as toras de Pinus taeda como para as de Eucalyptus dunnii, sendo que o lote 3 foi diferente estatisticamente de todos os demais. Para as toras de Eucalyptus dunnii, o lote 1 (outubro) teve o mesmo teor de umidade médio que o lote 4. Portanto, a biomassa colhida na entrada, durante e na saída do inverno tiveram os maiores teores de umidade, sendo que o Pinus taeda apresentou maiores teores de umidade inicial na biomassa em relação ao Eucalyptus dunnii, concordando com Nord-Larsen et al. (2011), que verificaram a mesma tendência quando compararam madeira de coníferas (gimnospermas) e folhosas (angiospermas dicotiledôneas).

O melhor comportamento na estocagem foi dos lotes 4 (agosto a fevereiro) e 1 (outubro a maio), sendo que o material foi coletado na saída do inverno ou primavera e estocado no verão ou até a entrada do 
inverno. Nesses dois lotes ocorreram também as maiores variações e perdas de teor de umidade, concordando com os resultados obtidos por Heding (1984), Nurmi (1995), Jirjis (1995), Pettersson e Nordfjell (2007) e Thörnqvist (1984b), que afirmaram que a secagem da biomassa florestal, tanto de árvores isoladas quanto de toras e resíduos florestais em pilhas é mais rápida nos meses de verão, ocorrendo reumidecimento do material durante o outono e inverno, se a estocagem ultrapassar os meses mais favoráveis à secagem, ou em épocas de maior umidade. Essa última afirmativa também foi verdadeira para este trabalho, pois observou-se que o tempo de estocagem de 4 meses foi melhor que o tempo de seis meses. Para Pinus taeda, ocorreu absorção de umidade após quatro meses de estocagem (Lotes 1) ou manutenção do teor de umidade ao longo do tempo (Lotes 2, 3 e 4). O Eucalyptus dunnii manteve o mesmo teor de umidade (Lote 4) ou continuou perdendo umidade (Lotes 1, 2 e 3) após o tempo de quatro meses. Porém, como o teor de umidade mínimo requerido para a biomassa, para a geração de energia, é de $30 \%$ ou menos (BRITO; BARRICHELO, 1982; GARSTANG et al., 2002; BRAND, 2010), o Eucalyptus dunnii alcançou esse parâmetro aos 4 meses, nos lotes 4 e 1 , precisando de mais tempo de estocagem nos lotes 2 e 3 . Para Pinus taeda, somente o lote 1 alcançou o teor de umidade desejado, com o tempo de estocagem de quatro meses (coleta feita em março - final do verão).
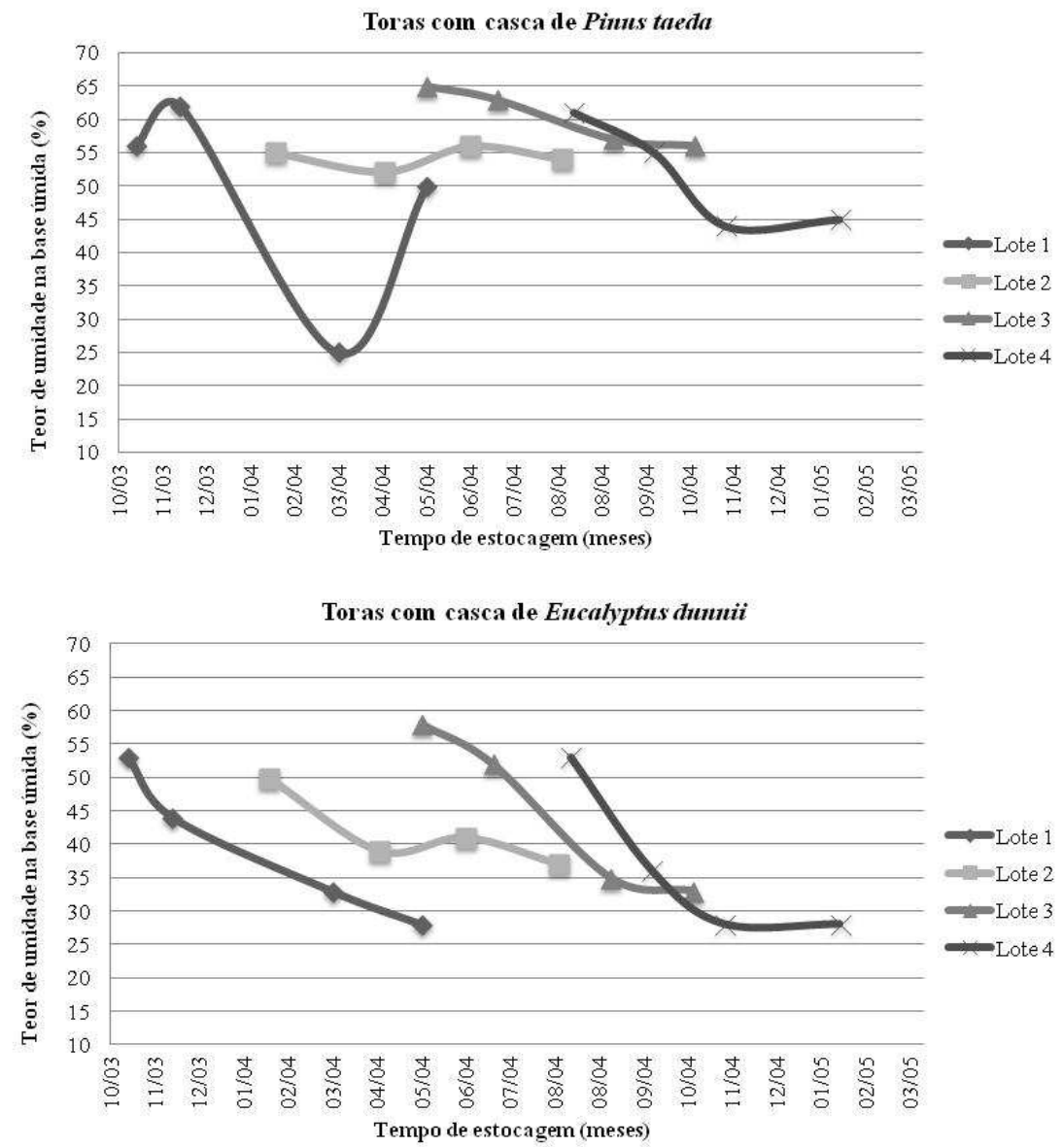

Figura 1. Variação no teor de umidade (\%) de toras de Pinus taeda e Eucalyptus dunnii em diferentes épocas de estocagem.

Figure 1. Variation in moisture content (\%) of logs of Pinus taeda and Eucalyptus dunnii depending on the storage season.

Portanto, tanto nos estudos realizados na Europa (HEDING, 1984; NURMI, 1995; JIRJIS, 1995; THÖRNQVIST, 1984b; PETTERSSON; NORDFJELL, 2007) como no Brasil, as diferenças de clima, relacionadas às épocas do ano, influenciaram na perda ou ganho de umidade no material sob estocagem. 
As maiores perdas de umidade ocorreram nos meses de primavera e verão (Lotes $1 \mathrm{e} 4$ ), e as menores, no inverno (Lotes 2 e 3) (Figura 1). Além disso, mesmo tendo havido perda de umidade nos meses mais favoráveis, se o material permaneceu sob estocagem, o mesmo voltou a absorver umidade nos meses menos favoráveis (Lote 2, tanto para Pinus taeda como para Eucalyptus dunnii) (Figura 1).

$\mathrm{O}$ fato de terem sido utilizadas pilhas pequenas $\left(10 \mathrm{~m}^{3}\right)$ também contribuiu para a melhor representação do efeito da época de estocagem sobre a variação de teor de umidade, como também observaram Thörnqvist (1985) e Jirjis (1995).

As variações estatísticas observadas permitem concluir que a época de estocagem influencia o comportamento da biomassa quanto à perda de umidade ao longo do tempo de estocagem, de forma que o tempo de estocagem poderá ser maior ou menor em função da época do ano em que a biomassa é colhida e mantida sob armazenamento. De forma geral, o efeito isolado da época de estocagem sobre a perda de umidade pode ser visualizado na figura 2.

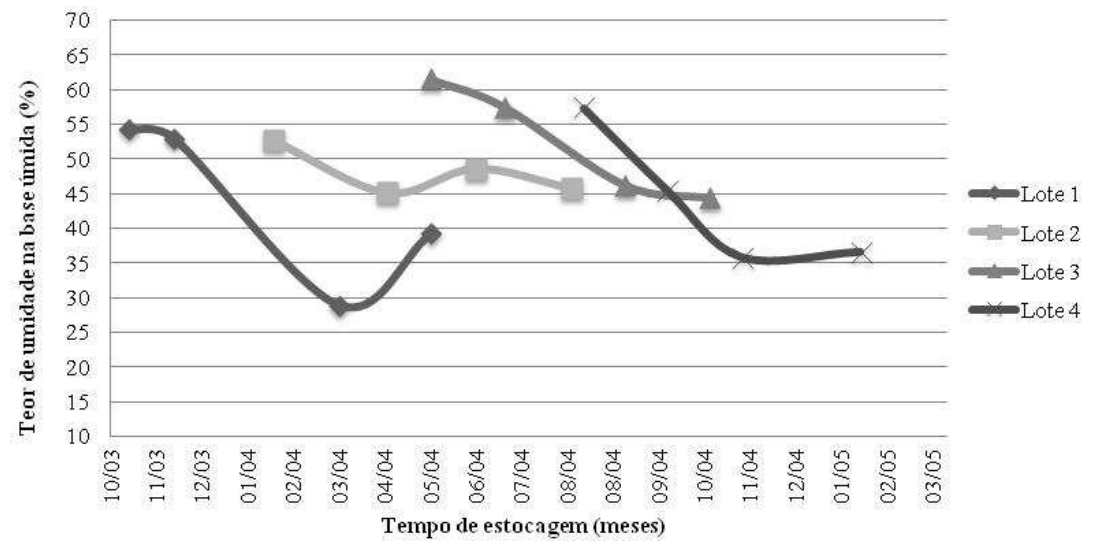

Figura 2. Variação do teor de umidade na base úmida em cada lote, em relação à época de estocagem da biomassa florestal.

Figure 2. Variation of moisture content for each lot in relation to the storage season.

O comportamento geral da época de estocagem de agosto a fevereiro (Lote 4) se iguala somente à época de outubro a maio (Lote 1), correspondendo às épocas de primavera e verão, como também são iguais as épocas de janeiro a agosto (Lote 2) e maio a novembro (Lote 3), correspondendo à saída do verão, outono e inverno. Assim, houve a tendência de se configurarem dois grupos de comportamento relativos às épocas do ano, verão e primavera e outono e inverno. Assim, o material coletado e estocado durante os meses de inverno apresentou maior teor de umidade, durante todo o período de estocagem, em comparação com o material coletado e estocado nos meses de verão, confirmando as afirmações feitas por Heding (1984), Thörnqvist (1984b), Nurmi (1995), Jirjis (1995), Pettersson e Nordfjell (2007), Nurmi e Hillebrand (2007), Nord-Larsen et al. (2011).

Deve-se ressaltar ainda que essa condição foi obtida em clima temperado, em que as condições de inverno e verão são bem definidas em relação à variação de temperatura e umidade relativa. No inverno são observadas temperaturas médias inferiores a $15^{\circ} \mathrm{C}$ e umidade relativa do ar superior a $80 \%$, enquanto no verão a temperatura média é em torno de $20{ }^{\circ} \mathrm{C}$ e a umidade relativa apresenta valores em torno de $75 \%$, em condições típicas de clima.

\section{Poder calorífico}

Com relação ao poder calorífico superior, os valores obtidos para as toras de Pinus taeda variaram entre 4722 e $4867 \mathrm{kcal} / \mathrm{kg}$, enquanto para as toras de Eucalyptus dunnii variaram de 4494 a 4684 $\mathrm{kcal} / \mathrm{kg}$. Na biomassa recém-colhida, o maior poder calorífico médio foi verificado na colheita feita em janeiro, para ambas as espécies. Isso era esperado, pois a composição química da madeira influencia o poder calorífico, e nas colheitas feitas no verão foram observados os maiores valores de extrativos solúveis em água, que se caracterizam por componentes que contribuem para o aumento do poder calorífico (BRAND, 2007). 
Apesar de serem observadas variações estatísticas significativas entre os lotes em cada tempo de estocagem (variação na LINHA da Tabela 4) para os materiais avaliados, essas variações não são importantes em termos práticos, visto que no uso da biomassa para geração de energia são consideradas impactantes diferenças superiores a $300 \mathrm{kcal} / \mathrm{kg}$ (BRAND, 2010) (Tabela 4 e Figura 3).

Tabela 4. Poder calorífico superior da biomassa florestal em função da época de estocagem.

Table 4. Gross calorific value of forest biomass as a function of storage season.

\begin{tabular}{lcccc}
\hline \multirow{2}{*}{ Época de estocagem } & \multicolumn{4}{c}{ Poder calorífico superior (kcal/kg) } \\
\cline { 2 - 5 } & $\begin{array}{c}\text { Lote 1 } \\
\text { (outubro a maio) }\end{array}$ & $\begin{array}{c}\text { Lote 2 } \\
\text { (janeiro a agosto) }\end{array}$ & $\begin{array}{c}\text { Lote 3 } \\
\text { (maio a novembro) }\end{array}$ & $\begin{array}{c}\text { Lote 4 } \\
\text { (agosto a fevereiro) }\end{array}$ \\
\hline Recém-colhido & $4796 \mathrm{ab}$ & Pinus taeda com casca \\
2 meses & $4836 \mathrm{ab}$ & $4867 \mathrm{a}$ & $4766 \mathrm{~b}$ & $4722 \mathrm{~b}$ \\
4 meses & $4819 \mathrm{a}$ & $4741 \mathrm{~b}$ & $4781 \mathrm{ab}$ & $4866 \mathrm{a}$ \\
6 meses & $4723 \mathrm{~b}$ & $4838 \mathrm{a}$ & $4855 \mathrm{a}$ & $4843 \mathrm{a}$ \\
\hline \multicolumn{4}{c}{ Eucalyptus dunnii com casca } \\
\hline Recém-colhido & $4494 \mathrm{a}$ & $4571 \mathrm{a}$ & $4855 \mathrm{a}$ \\
2 meses & $4565 \mathrm{~b}$ & $4586 \mathrm{~b}$ & $4544 \mathrm{a}$ & $4560 \mathrm{a}$ \\
4 meses & $4563 \mathrm{a}$ & $4634 \mathrm{a}$ & $4602 \mathrm{~b}$ & $4707 \mathrm{a}$ \\
6 meses & $4548 \mathrm{~b}$ & $4531 \mathrm{~b}$ & $4634 \mathrm{a}$ & $4636 \mathrm{a}$ \\
\hline
\end{tabular}

Nota: Médias seguidas da mesma letra, na linha, não diferem significativamente entre si (Tukey $\mathrm{P}>0,05$ ).
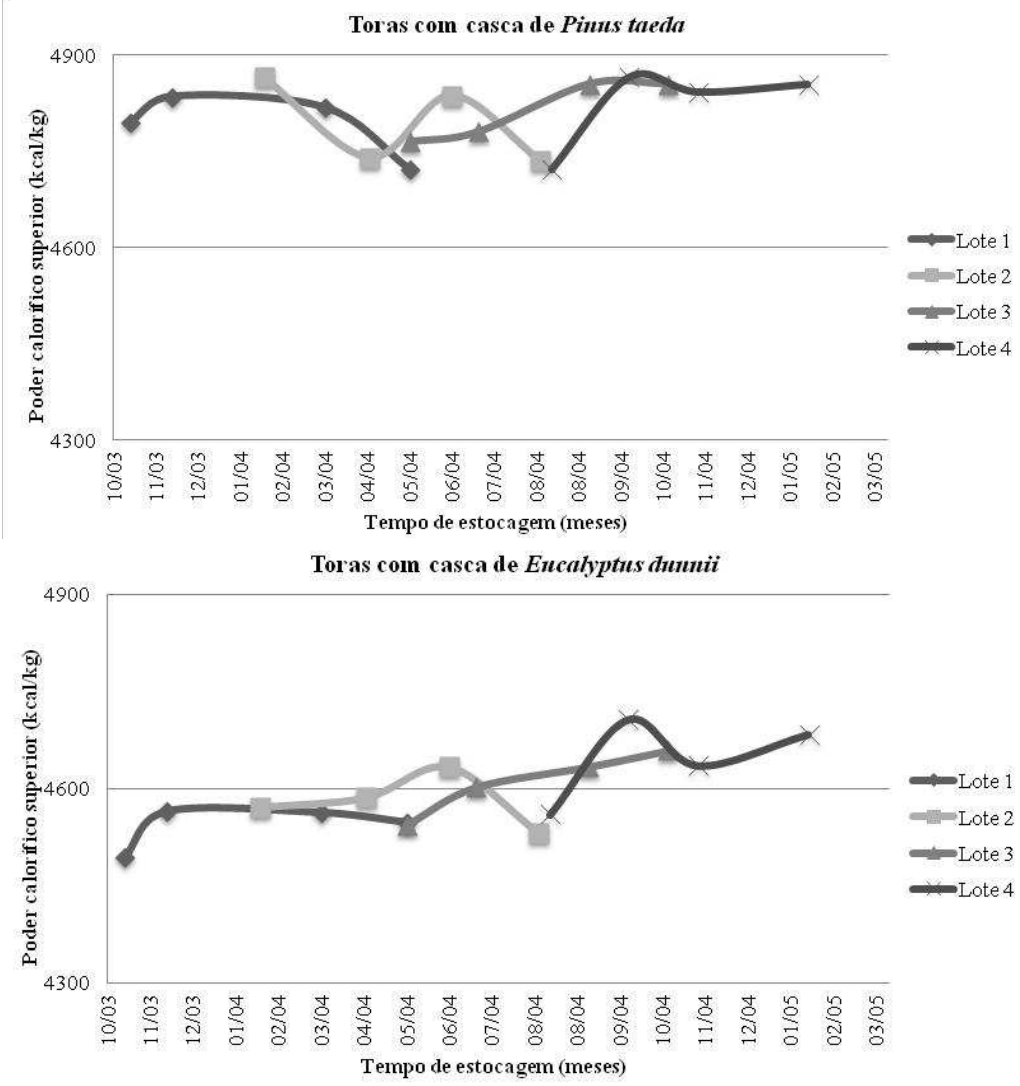

Figura 3. Variação no poder calorífico superior de toras de Pinus taeda e Eucalyptus dunnii em diferentes épocas de estocagem.

Figure 3. Variation in gross calorific value ( $\mathrm{kcal} / \mathrm{kg}$ ) of logs of Pinus taeda and Eucalyptus dunnii depending on the storage season. 
Tanto para Pinus taeda como para Eucalyptus dunnii, os maiores valores de poder calorífico superior, ao longo da estocagem, foram observados com maior frequência no lote 4 (agosto a fevereiro).

As variações observadas ao longo da estocagem caracterizadas como ganhos ou perdas energéticas também são insignificantes, pois são inferiores a $300 \mathrm{kcal} / \mathrm{kg}$, para ambas as espécies. Pode ser observada uma tendência de ganho energético para o lote 3 (maio a novembro), para ambas as espécies avaliadas, tendo o mesmo comportamento descrito por Thörnqvist (1984a). Esse autor afirmou que a biomassa que foi coletada e estocada em pilhas na forma de toras, durante o inverno teve aumento do seu conteúdo energético. Isso porque no inverno predominam as condições adversas para o desenvolvimento da biodegradação, impedindo assim a perda de massa pela degradação por microorganismos xilófagos.

Os lotes le 4 tiveram uma tendência de aumento, seguido de redução do poder calorífico, e o lote 3 não teve um comportamento definido para nenhuma das espécies avaliadas.

O poder calorífico líquido variou em função da época de estocagem, como esperado, em função da sua relação estreita com o teor de umidade (Tabela 5 e Figuras 4 e 5).

Tabela 5. Poder calorífico líquido da biomassa florestal em função da época de estocagem.

Table 5. Net calorific value of forest biomass as a function of storage season.

\begin{tabular}{lcccc}
\hline \multirow{2}{*}{ Época de estocagem } & \multicolumn{4}{c}{ Poder calorífico líquido (kcal/kg) } \\
\cline { 2 - 5 } & $\begin{array}{c}\text { Lote 1 } \\
\text { (outubro a maio) }\end{array}$ & $\begin{array}{c}\text { Lote } 2 \\
\text { (janeiro a agosto) }\end{array}$ & $\begin{array}{c}\text { Lote 3 } \\
\text { (maio a novembro) }\end{array}$ & $\begin{array}{c}\text { Lote } 4 \\
\text { (agosto a fevereiro) }\end{array}$ \\
\hline Recém-colhido & $1657 \mathrm{a}$ & Pinus taeda com casca \\
2 meses & $1357 \mathrm{c}$ & $1719 \mathrm{a}$ & $1201 \mathrm{c}$ & $1341 \mathrm{~b}$ \\
4 meses & $3234 \mathrm{a}$ & $1822 \mathrm{a}$ & $1273 \mathrm{~d}$ & $1728 \mathrm{~b}$ \\
6 meses & $1889 \mathrm{~b}$ & $1664 \mathrm{c}$ & $1614 \mathrm{c}$ & $2281 \mathrm{~b}$ \\
\hline \multicolumn{5}{c}{ Eucalyptus dunnii com casca } \\
\hline Recém-colhido & $1656 \mathrm{~b}$ & $1828 \mathrm{a}$ & $1672 \mathrm{c}$ & $2219 \mathrm{a}$ \\
2 meses & $2125 \mathrm{c}$ & $2331 \mathrm{~b}$ & $1423 \mathrm{c}$ & $2677 \mathrm{~b}$ \\
4 meses & $2655 \mathrm{~b}$ & $2311 \mathrm{c}$ & $1755 \mathrm{~d}$ & $2927 \mathrm{a}$ \\
6 meses & $2887 \mathrm{~b}$ & $2394 \mathrm{~d}$ & $2605 \mathrm{~b}$ & $2984 \mathrm{a}$ \\
\hline
\end{tabular}

Nota: Médias seguidas da mesma letra, na linha, não diferem significativamente entre si (Tukey P >0,05).

Os maiores valores de poder calorífico líquido na biomassa recém-colhida foram observados no lote 2, para ambas as espécies analisadas, visto que nessa época também foram registrados os menores teores de umidade inicial e maior poder calorífico superior. No entanto, durante a estocagem, esse lote (janeiro a agosto) teve o pior desempenho, registrando os mais baixos ganhos energéticos, em relação aos valores iniciais (biomassa recém-colhida), concordando com Thörnqvist (1986), que afirmou que as variações energéticas dependem das diferentes espécies de árvores e conteúdos de umidade no momento da confecção das pilhas.

Para as toras de Pinus taeda, o maior ganho energético foi de $95 \%$ em relação aos valores iniciais, para o lote 1, com quatro meses de estocagem, atingindo o valor médio de poder calorífico líquido de $3200 \mathrm{kcal} / \mathrm{kg}$. O lote 4 ficou em segundo lugar, com $70 \%$ de ganho energético com quatro meses de estocagem. Já para as toras de Eucalyptus dunnii, os maiores ganhos foram no lote 3, com $91 \%$ e $83 \%$ de ganho energético com seis e quatro meses de estocagem, respectivamente. O lote 4 ficou em segundo lugar, com ganhos de $78 \%$ e $75 \%$ com seis e quatro meses de estocagem.

Avaliando conjuntamente o percentual de ganho energético e os valores finais obtidos, os lote 4 (agosto a fevereiro) e 1 (outubro a maio) tiveram os melhores desempenhos energéticos ao longo do tempo de estocagem, para ambas as espécies.

Considerando que, no Brasil, a maior demanda por energia é nos meses de verão, isso coincide com a época em que a biomassa estocada teve as melhores condições energéticas, proporcionando maior rendimento nas plantas de geração de energia. Essa característica é o oposto do que ocorre nos países do hemisfério Norte, onde a maior demanda energética é nos meses de inverno, cujos os ganhos energéticos durante a estocagem são menores.

Portanto, se o material for coletado em agosto e permanecer sob estocagem até outubro ou até dezembro, o material terá melhor qualidade energética na época do ano em que a demanda energética é 
maior, proporcionando maior eficiência e rendimento na planta de geração de energia.
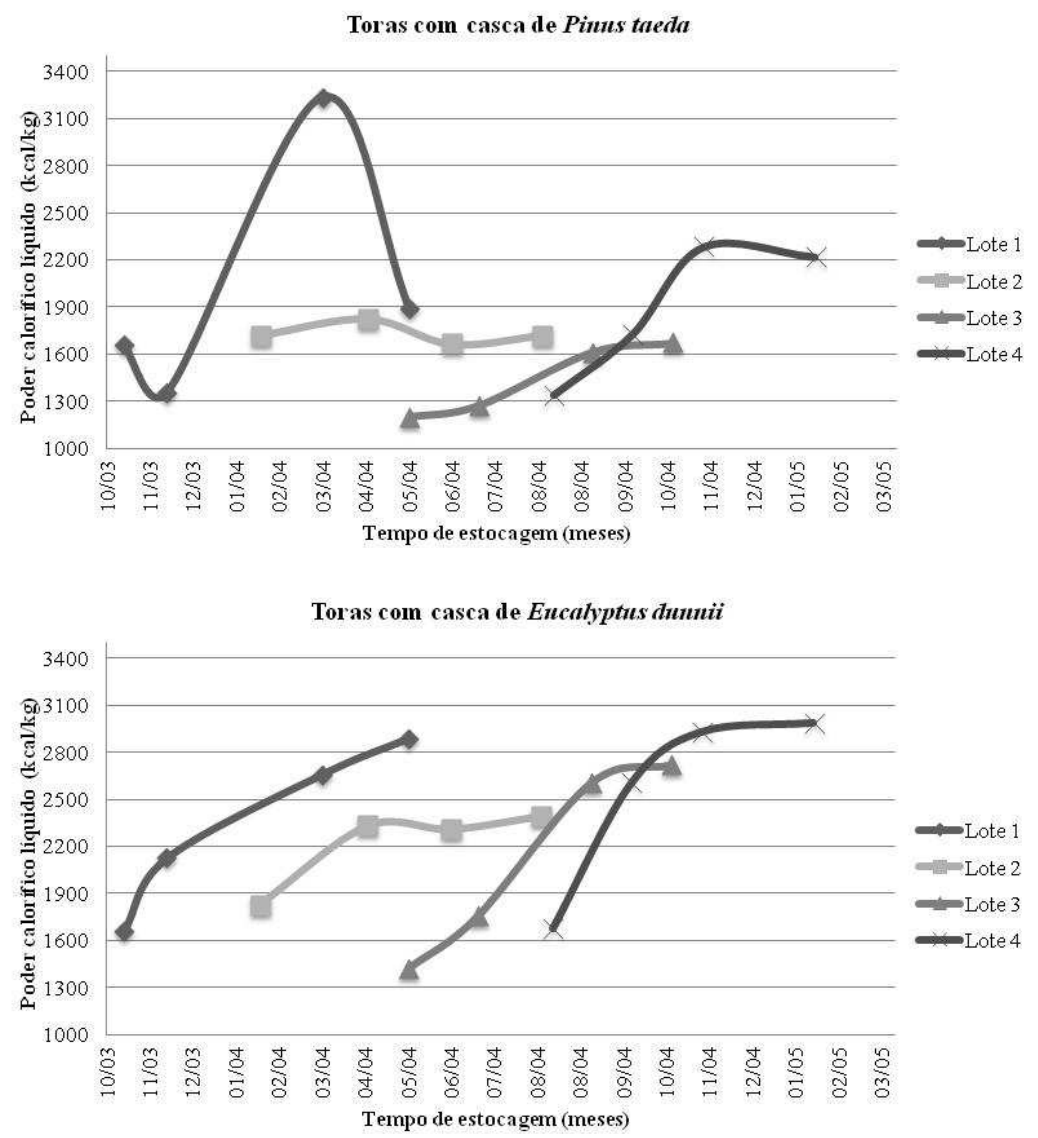

Figura 4. Variação no poder calorífico líquido de toras de Pinus taeda e Eucalyptus dunnii em diferentes épocas de estocagem.

Figure 4. Variation in net calorific value (kcal/kg) of $\operatorname{logs}$ of Pinus taeda and Eucalyptus dunnii depending on the storage season.

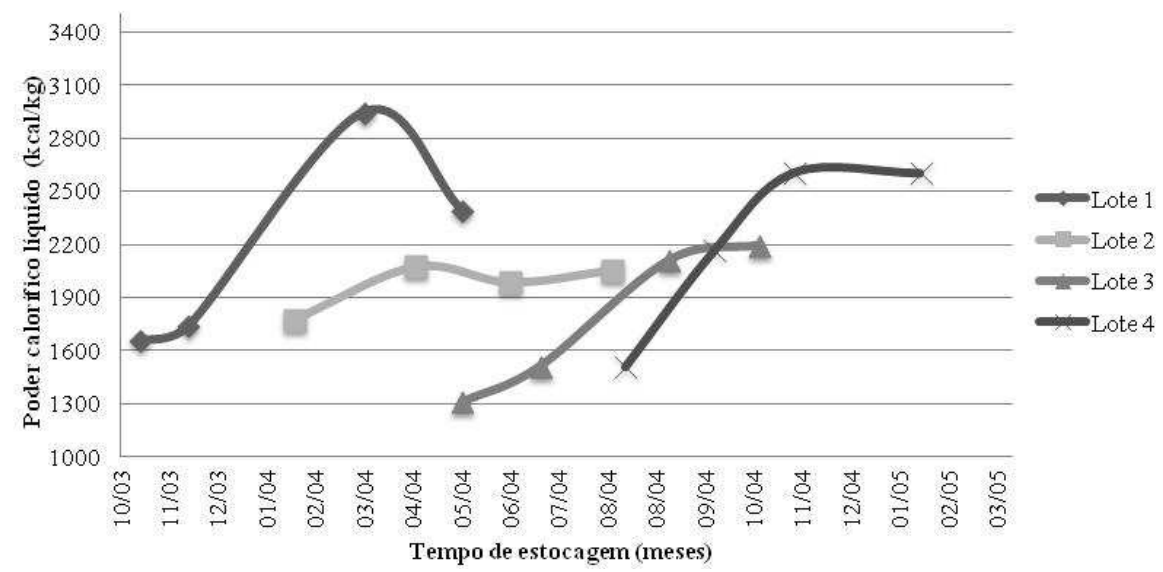

Figura 5. Variação do poder calorífico líquido em cada lote, em relação à época de estocagem da biomassa florestal.

Figure 5. Variation of net calorific value for each lot in relation to the storage season. 
No entanto, essa estratégia terá um potencial competitivo somente quando for possível o planejamento das questões logísticas, utilizando-se a estocagem como ferramenta para a melhoria da qualidade da biomassa para a geração de energia, considerando-se que a planta de geração tenha matériaprima em abundância e espaço físico para a realização da operação de estocagem. Nas demais épocas do ano, a coleta e a estocagem da biomassa continuarão a ser realizadas, não tendo, no entanto, tanto ganho energético.

\section{CONCLUSÕES}

- A época de estocagem teve influência sobre a qualidade energética da biomassa durante a estocagem.

- A época de estocagem teve influência sobre a intensidade e velocidade de perda de umidade e sobre o ganho e perda energética da biomassa.

- Para Pinus taeda, em todas as épocas de estocagem avaliadas, o tempo de estocagem deve ser de no máximo 4 meses, não havendo ganho energético após esse período.

- Para Eucalyptus dunnii, em todas as épocas avaliadas, a biomassa continua tendo melhoria das propriedades energéticas até seis meses de estocagem.

- No sul do Brasil, para ambas as espécies, e para todas as propriedades avaliadas, as melhores épocas de estocagem foram de agosto a fevereiro (lote 4) e outubro a maio (lote 1), quando foram registradas as maiores perdas de umidade e maiores ganhos energéticos.

- A biomassa florestal colhida na saída do inverno ou início da primavera e que permaneceu sob estocagem durante o verão até o início do inverno apresentou melhor qualidade energética.

- A estocagem nos meses de inverno, com colheita da biomassa no verão (janeiro a agosto) é pouco recomendável, devido ao pequeno ganho energético.

\section{REFERÊNCIAS}

ANDERSSON, G.; ASIKAINEN, A.; BJÖRHEDEN, R.; HALL, P. W.; HUDSON, J. B.; JIRJIS, R.; MEAD, D.; NURMI, J.; WEETMAN, G. Production of forest energy. In: RICHARDSSON, J.; BJÖRHEDEN, HAKKILA, P.; LOWE, A. T.; SMITH, C. T. Bioenergy from sustainable forestry, guiding principles and practice. Dordrecht: Kluwer Academic Publishers, 2002, ISBN 1-4020-0676-4.

ASSOCIAÇÃO BRASILEIRA DE NORMAS TÉCNICAS. NBR 14929: Madeira - Determinação do teor de umidade de cavacos - Método por secagem em estufa. Rio de Janeiro, 2003.

BRAND, M. A. Energia de Biomassa Florestal. Rio de Janeiro: Interciência, 2010. 114 p.

Qualidade da biomassa florestal para o uso na geração de energia em função da estocagem. 165 p. Tese (Pós-Graduação em Ciências Florestais) - Universidade Federal do Paraná, Curitiba, 2007.

BRITO, J. O.; BARRICHELO, L. E. G. Aspectos técnicos da utilização da madeira e carvão vegetal como combustíveis. In: Seminário de Abastecimento Energético Industrial com Recursos Florestais, 2., 1982, São Paulo. Anais... São Paulo: Governo do Estado de São Paulo, 1982. p. 101 - 137.

DEUTSCHES INSTITUT FÜR NORMUNG e. V. DIN 51900: Determining the gross calorific value of solid and liquid fuels using the bomb calorimeter, and calculation of net calorific value. Berlim, 2000.

Empresa de Pesquisa Agropecuária e Extensão Rural de Santa Catarina. EPAGRI. Estação meteorológica. Lages: Estação Experimental de Pesquisa Agropecuária de Lages. 2006.

GARSTANG, J.; WEEKES, A.; POULTER, R.; BARTLETT, D. Identification and characterisation of factors affecting losses in the large-scale, non-ventilated bulkstorage of wood chips and development of best storage practices. FES B/W2/00716/RESP.DTI/Pub urn 02/1535, 2002. 116 p. Relatório técnico.

HEDING, N. The critical moisture content. In: Conference held by the International Energy Agency (IEA) - Forestry Energy Programme Group C - Storing, drying and internal handling of wood fuels, 1984, Denmark. Proceedings... Denmark: Danish Institute of Forest Technology, 1984. p. 6 - 11.

JIRJIS, R. Storage and drying of wood fuel. Biomass and Bioenergy. v. 9, issue 1-5, p. 181 - 190, 1995. 
LEITE, N. B.; FERREIRA, M.; RAMOS, P. G.; GUTIERREZ NETO, F. Efeito de geadas sobre diversas espécies/procedências de Eucalyptus spp. introduzidas na região de Lages - Santa Catarina. IPEF, v. 7, p. $101-114,1973$.

NORD-LARSEN, T.; BERGSTEDT, A.; FARVER, O.; HEDING, N. Drying of firewood e the effect of harvesting time, tree species and shelter of stacked Wood. Biomass and bioenergy, v. 35, p. 2993 - 2998 , 2011.

NURMI, J. Measurement and evaluation of wood fuel. Biomass and Bioenergy, v. 2, issue 1-6, p. 157 171. 1992.

NURMI, J. The effect of whole-tree storage on the fuelwood properties of short-rotation Salix crops. Biomass and Bioenergy, v. 8, issue 4, p. 245 - 249, 1995.

NURMI, J.; HILLEBRAND, K. The characteristics of whole-tree fuel stocks from silvicultural cleanings and thinnings. Biomass and Bioenergy, v. 31, p. 381 - 392, 2007.

PETTERSSON, M.; NORDFJELL, T. Fuel quality changes during seasonal storage of compacted logging residues and young trees. Biomass and Bioenergy, v. 31, p. 782 - 792, 2007.

RÖSER, D.; MOLA-YUDEGO, B.; SIKANEN, L.; PRINZ, R.; GRITTEN, D.; EMER, B.; VÄÄTÄINEN, KARI; ERKKILA, A. Natural drying treatments during seasonal storage of Wood for bioenergy in different European locations. Biomass and bioenergy, v. 35, p. 4238 - 4247, 2011.

THÖRNQVIST, T. Drying and storage of forest residues for energy production. Biomass, England, v. 7, p. $125-134,1985$.

Energy change due to storage of logging residues. In: International Conference on Bioenergy, 1984, Göteborg. Proceedings... Sweden: Swedish University of Agricultural Sciences Department of Forest Products, 1984a. Research notes n ${ }^{\circ} 152$.

Projekt storskalig säsongslagring av trädbraänsle - en sammanfattning av etapp 1. Large-scale seasonal storage of tree fuel project - summary of phase 1. Sweden: The Swedish University of Agricultural Sciences. Department of Forest Products, 1986. 50 p. Report no 188.

Storing of forest residues and comminuted fuels from forest residues. In: Conference held by the International Energy Agency (IEA) - Forestry Energy Programme Group C - Storing, drying and internal handling of wood fuels, 1984, Denmark. Proceedings... Denmark: Danish Institute of Forest Technology, 1984b. p. $16-18$. 